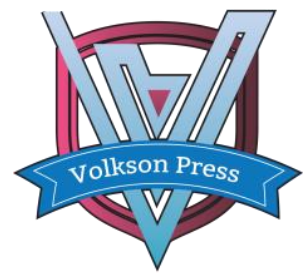

\title{
Research on the Influence of Environmental Regulation on Business Performance: The Moderating Role of Green Technology Innovation
}

\author{
XIANG Li ${ }^{1}{ }^{2}$, HU Long-ying ${ }^{1}$
}

${ }^{1}$ School of Management, Harbin Institute of Technology, Harbin, China

${ }^{2}$ Hezhou College, Hezhou, China

*xiang30185@163.com

This is an open access article distributed under the Creative Commons Attribution License, which permits unrestricted use, distribution, and reproduction in any medium, provided the original work is properly cited.

\section{ARTICLE DETAILS}

\section{Article History:}

Received 02 october 2017

Accepted 06 october 2017

Available online 11 october 2017

\section{Keywords:}

Environmental regulation,

Business performance, Green

technology innovation

\section{ABSTRACT}

Based on the panel data of 27 industrial sectors in China from 2003 to 2011, the influence of environmental regulation on the business performance was tested by using the fixed effect model, and the moderating role of green technology innovation is discussed from the aspects of green product innovation and green process innovation. The results show that environmental regulation has a significant positive effect on the performance of industrial enterprises. Green product innovation has a positive impact on business performance, but the impact of green process innovation on business performance is not significant. Green product innovation and green process innovation have negative moderating impacts on the relationship of environmental regulation and business performance.

\section{Introduction}

Porter (1991) put forward the "Porter hypothesis" theory, and he argues that strengthening environmental regulation can encourage enterprises to improve pollution control capacity and product technology content by increasing R\&D inputs, and then reduce the adverse effects of environmental regulation on business performance. Industry is an important engine of China's economic growth, but the high growth of Chinese industry has the characteristics of high investment, high energy consumption and high emission. In recent years, China's industrial "three wastes" and other pollutants rose sharply, and the regional resources and environmental problems became increasingly serious. Industrial enterprises are the main undertakers of technological innovation activities, which play an important role in R\&D investment, patent application, scientific and technological achievements transformation and so on. China's industrial enterprises urgently need to vigorously carry out green technological innovation activities, reduce environmental pollution and energy consumption, as soon as possible to achieve the transformation of green development. In this context, this paper studies the relationship between environmental regulation, green technology innovation and business performance, and the research results can contribute to evaluate the concrete implementation performance of environmental regulation policies and carry out the green technology innovation activities as well as the improvement of operating performance.

\section{Theoretical Analysis and Research Hypothesis}

\subsection{The Impact of Environmental Regulation on Business} Performance

Porter (1991) believes that the proper implementation of environmental regulation can improve business performance. The conclusion is confirmed by Berman et al. (2001) [1]. However, Palmer et al. (1995) put forward the "expensive regulation hypothesis", which holds that strict environmental regulation will lead to high environmental regulatory costs, and reduce the business performance [2]. This is consistent with the conclusions of Dale et al. (1990) [3]. Although the impact of environmental regulation on business performance is uncertain, there is a significant correlation between them. Therefore, this paper presents hypothesis 1 .

Hypothesis 1: There is a significant correlation between environmental regulation and business performance.

\subsection{The Moderating Effect of Green Technology Innovation}

Chen Jin et al. (2002) concluded that the green technology innovation had a significant impact on the environmental performance and economic performance ${ }^{[4]}$. Cao Xia et al. (2015) found that high intensity of pollution tax and moderate innovation compensation can promote green technology innovation [5]. Enterprises which carry out green technology innovation activities need a lot of R\&D investment, and earnings are not obvious in short term. In the context of environmental regulation, the enterprise's green product innovation and green process innovation may have negative impacts on its business performance. Therefore, this paper proposes the following assumptions.

Hypothesis 2: Green product innovation plays a moderating role in the relationship between environmental regulation and business performance.

Hypothesis 3: Green process innovation plays a moderating role in the relationship between environmental regulation and business performance.

\section{Research Design}

\subsection{Research Sample Selection and Data Sources}

As China began to implement the new national economic industry classification standard in 2003, and "China Statistical Yearbook" and "China Industrial Statistics Yearbook" after 2012 are no longer provided industrial sub-industry output data, so the sample interval is set from 2003 to 2011. In order to maintain statistical consistency, this paper is based on the industry classification in 2007, excluding the "waste scrap" industry and "handicrafts and other manufacturing" industry, and some industries were merged to get 27 representative industries as the study sample of this paper. The data mainly come from "China Statistical Yearbook", "China Science and Technology Statistical Yearbook", "China Environment Statistical Yearbook" and "China Energy Statistical Yearbook" from 2004 to 2012.

\subsection{Variable Measurement}

Dependent variable: business performance. The net profit margin of enterprises is used to measure the operating performance of industrial enterprises ( $e p r$ ), and the ratio of total profits and sales income of large and medium-sized industrial enterprises is measured. 
Independent variables: environmental regulation. Five specific indexes of wastewater discharge compliance rate, sulfur dioxide removal rate, soot removal rate, dust removal rate and solid waste comprehensive utilization rate were selected, and the environmental regulation intensity ( $e r i$ ) of industrial industry was measured by comprehensive index method [6].

Moderators: Green product innovation ( $g p t$ ) is measured by the ratio of energy consumption to the output value of new products. The green process innovation ( $g p r$ ) is measured by the sum of the expenditure of the R\&D fund and the investment of the technological transformation [7].

Control variable. The scale of the enterprise ( $s c a$ ) is measured by the ratio of the gross output value and the number of enterprises. This paper takes the industry output value of the proportion of state-owned enterprises as a proxy indicator to measure the ownership structure ( $s t r$ ). The management cost ( $m g e$ ) is measured by the proportion of the management cost of the large and medium-sized industrial enterprises in the main business cost. The degree of competition in the industry ( $i c n$ ) is referenced to the practice of Xiao Wen et al. (2014), by selecting four specific indicators and calculating the arithmetic mean [8]. Pollution intensity ( piy ) is referenced to the practice of Wang Jie et al. (2014), by selecting five specific indicators, and using linear standardization and equal weight method and the average method to calculate [6]. Government subsidy ( $g o f$ ) is measured by the proportion of government funds in the activities of science and technology. The financing environment ( fie ) is measured by the proportion of financial institutions' loans to the proportion of science and technology activities.

\section{Empirical Analysis}

\subsection{Data Validation and Model Selection}

The correlation analysis of the sample data shows that the correlation coefficient between the variables is not high, and the VIF value of each variable is less than 10 , which indicates that there is no serious multicollinearity problem in the model. The data stability test results show that there is no serious unit root for each sample variable. F test results show that the test statistic of each model is significant at $1 \%$ level, it can be considered that the fixed effect model is superior to the mixed regression model. The Hausman test results also suggest that a fixed effect model should be used instead of a random effect model. Therefore, this paper selected individual fixed effect model for regression analysis. In order to reduce the possible heteroscedasticity, this paper takes natural logarithm of each variable.

Table $1 \cdot$ Regression analysis results

\begin{tabular}{|c|c|c|c|c|}
\hline \multirow{2}{*}{ Variable } & \multicolumn{4}{|c|}{ Dependent variable : lnepr } \\
\hline & Model 1 & Model 2 & Model 3 & Model 4 \\
\hline $\ln s c a$ & $\begin{array}{c}-0.024^{* *} \\
(-2.07) \\
\end{array}$ & $\begin{array}{l}-0.021^{*} \\
(-1.86) \\
\end{array}$ & $\begin{array}{l}-0.016 \\
(-1.43) \\
\end{array}$ & $\begin{array}{l}-0.022^{*} \\
(-1.96) \\
\end{array}$ \\
\hline lnstr & $\begin{array}{l}0.043 \\
(1.58)\end{array}$ & $\begin{array}{l}0.052^{*} \\
(1.95)\end{array}$ & $\begin{array}{l}0.048^{*} \\
(1.79)\end{array}$ & $\begin{array}{l}0.034 \\
(1.28)\end{array}$ \\
\hline $\ln m g e$ & $\begin{array}{c}0.123^{* * *} \\
(3.09)\end{array}$ & $\begin{array}{c}0.121^{* * *} \\
(3.14)\end{array}$ & $\begin{array}{c}0.107^{* * * *} \\
(2.79)\end{array}$ & $\begin{array}{c}0.110^{* * * *} \\
(2.89)\end{array}$ \\
\hline $\operatorname{lnicn}$ & $\begin{array}{c}0.097^{* * * *} \\
(3.12)\end{array}$ & $\begin{array}{c}0.093^{* * *} \\
(3.07)\end{array}$ & $\begin{array}{c}0.094^{* * * *} \\
(3.06)\end{array}$ & $\begin{array}{c}0.086^{* * * *} \\
(2.89)\end{array}$ \\
\hline $\ln p i y$ & $\begin{array}{l}-0.016 \\
(-1.04)\end{array}$ & $\begin{array}{c}-0.045^{* * *} \\
(-2.70)\end{array}$ & $\begin{array}{c}-0.043^{* *} \\
(-2.57)\end{array}$ & $\begin{array}{c}-0.042^{* * *} \\
(-2.60)\end{array}$ \\
\hline $\ln g o f$ & $\begin{array}{l}-0.010 \\
(-0.96) \\
\end{array}$ & $\begin{array}{c}-0.004 \\
(-0.42) \\
\end{array}$ & $\begin{array}{l}-0.005 \\
(-0.48) \\
\end{array}$ & $\begin{array}{l}-0.011 \\
(-1.05) \\
\end{array}$ \\
\hline $\ln f i e$ & $\begin{array}{l}0.016^{*} \\
(2.48)\end{array}$ & $\begin{array}{c}0.014^{* * *} \\
(2.27)\end{array}$ & $\begin{array}{l}0.012^{*} \\
(1.94)\end{array}$ & $\begin{array}{c}0.019^{* * * *} \\
(2.96)\end{array}$ \\
\hline $\ln e r i$ & & $\begin{array}{c}0.026^{* * *} \\
(3.65)\end{array}$ & $\begin{array}{c}0.025^{* * * *} \\
(3.60)\end{array}$ & $\begin{array}{c}0.153^{* * * *} \\
(3.70)\end{array}$ \\
\hline $\ln g p t$ & & & $\begin{array}{c}0.013^{* * * *} \\
(2.84) \\
\end{array}$ & $\begin{array}{c}0.002 \\
(0.29) \\
\end{array}$ \\
\hline $\ln g p r$ & & & $\begin{array}{l}0.006 \\
(0.59) \\
\end{array}$ & $\begin{array}{l}-0.018 \\
(-1.45) \\
\end{array}$ \\
\hline $\ln g p t \times \ln e r i$ & & & & $\begin{array}{c}-0.004^{* *} \\
(-2.15)\end{array}$ \\
\hline $\ln g p r \times \ln e r i$ & & & & $\begin{array}{c}-0.012^{* * * *} \\
(-3.49)\end{array}$ \\
\hline cons & $\begin{array}{c}-1.215^{* * *} \\
(-7.40) \\
\end{array}$ & $\begin{array}{c}-1.278^{* * *} \\
(-7.97) \\
\end{array}$ & $\begin{array}{c}-1.211^{* * *} \\
(-4.96) \\
\end{array}$ & $\begin{array}{c}-0.916^{* * *} \\
(-3.57) \\
\end{array}$ \\
\hline
\end{tabular}

Note: Values in parentheses are $t$ values. $* * *, * *, *$, represent $1 \%, 5 \%$ and $10 \%$ significance levels respectively.

\subsection{Hypothesis Test}

In this paper, we use the sequential test method of Muller et al. (2005) to sequentially introduce the regression variables of the control variables, the moderators and the independent variables, the moderators and the independent variables into the regression models to test the theoretical hypotheses. The results are shown in table 1.

Model 1 represents the regression of the control variable against the dependent variable. The variable size, management cost, industry competition intensity and financing environment have significant positive impact. The pollution intensity and government subsidy negatively affect the performance of the enterprise, and the ownership structure has a positive impact on business performance, but not significant.

Model 2 is the introduction of independent environmental regulation on the basis of model 1, and the regression results show that environmental regulation has a significant positive effect on the business performance of industrial enterprises. With the improvement of environmental regulation intensity, the performance of industrial enterprises will be increased. Environmental regulation is an effective way for industrial enterprises to increase their economic returns. This validates the hypothesis 1 .

Model 3 is the introduction of green product innovation and green technology innovation based on the model 2, and the regression results show that the coefficient of green product innovation is significantly positive, indicating that the green product innovation positively affects the business performance. Coefficient of green technology innovation is positive but not significant, indicating that the relationship between green process innovation and business performance needs to be further tested.

Model 4 joins the green product innovation and environmental regulation of the interactive items, green process innovation and environmental regulation of the interactive items based on the model 3 , and the test results show that the environmental regulation also has a positive impact on business performance. The coefficients of the interaction terms are significantly negative, and the results show that green product innovation and green process innovation play a negative regulatory role in the relationship between environmental regulation and enterprise performance. The negative regulation effect of green process innovation is more obvious. This verifies the hypothesis 2 and hypothesis 3 .

\section{Conclusions}

The empirical results of this paper show that there is a significant positive correlation between environmental regulation and business performance of industrial enterprises. Green product innovation has a positive impact on business performance. The positive impact of green process innovation on business performance is not significant. The impact of environmental regulation on the performance of enterprises is influenced by the green technology innovation. Green product innovation and green process innovation play a negative regulatory role in the relationship between environmental regulation and business performance. The government should promote the effective use of "innovation compensation" according to the cost benefit, the efficiency of regulation and the actual situation of industrial enterprises.

\section{References}

[1] Berman E., Bui L.. Environmental Regulation and Productivity: Evidence from Oil Reveries. The Review of Economics and Statistic, 2001, 88(3):498-510.

[2] Palmer, K. L., Wallace E. Oates, Paul R. Portney. Tightening Environmental Standards: The Benefit-cost or the No-cost paradigm? Journal of Economic Perspectives, 1995, 9(4):119-132.

[3] Dale, W., Peter, J.. Environmental Regulation and U.S Economic Growth. The Rand Journal of Economics, 1990, 21(2):313-340.

[4] Chen Jin, Liu Jing-jiang, Yang Fa-ming. Experimental Research on Green Technology Innovation Audit. Science Research, 2002 (2):107-112.

[5] Cao Xia, Zhang Lu-peng. Evolutionary Game Analysis of Enterprise Green Technology Innovation Diffusion. China's Population, Resources and Environment, 2015(7):68-76. 
[6] Wang Jie, Liu Bin. Environmental Regulation and Enterprise Total Factor Productivity: An Empirical Analysis Based on the Data of Chinese Industrial Enterprises. China Industrial Economy, 2014(3):44-56.

[7] Li Wan-hong, Bi Cheng, Cao Xia. The Effect of Environmental Regulation Tools on Green Technology Innovation of Manufacturing
Enterprises: A Case Study of Paper and Paper Products Enterprises. Systems Engineering, 2013(10):112-122.

[8] Xiao Wen, Lin Gao-bang. Government Support, Research Management and Technology Innovation Efficiency: An Empirical Analysis Based on Chinese industries. Management World, 2014(4): 71-80. 